\title{
Adverse events in psychiatry: a national cohort study in Sweden with a unique psychiatric trigger tool
}

\author{
Lena Nilsson ${ }^{1,2^{*}}$ D, Madeleine Borgstedt-Risberg ${ }^{3}$, Charlotta Brunner ${ }^{4}$, Ullakarin Nyberg ${ }^{5}$, Urban Nylén ${ }^{6}$, \\ Carina Ålenius ${ }^{7}$ and Hans Rutberg ${ }^{7}$
}

\begin{abstract}
Background: The vast majority of patient safety research has focused on somatic health care. Although specific adverse events (AEs) within psychiatric healthcare have been explored, the overall level and nature of AEs is sparsely investigated.

Methods: Cohort study using a retrospective record review based on a two-step trigger tool methodology in the charts of randomly selected patients 18 years or older admitted to the psychiatric acute care departments in all Swedish regions from January 1 to June 30, 2017. Hospital care together with corresponding outpatient care were reviewed as a continuum, over a maximum of 3 months. The AEs were categorised according to type, severity and preventability.

Results: In total, the medical records of 2552 patients were reviewed. Among the patients, 50.4\% were women and 49.6\% were men. The median (range) age was 44 (18-97) years for women and 44.5 (18-93) years for men.

In 438 of the reviewed records, 720 AEs were identified, corresponding to the AEs identified in $17.2 \%$ [95\% confidence interval, 15.7-18.6] of the records. The majority of AEs resulted in less or moderate harm, and $46.2 \%$ were considered preventable. Prolonged disease progression and deliberate self-harm were the most common types of AEs. AEs were significantly more common in women (21.5\%) than in men (12.7\%) but showed no difference between age groups. Severe or catastrophic harm was found in $2.3 \%$ of the records, and the majority affected were women (61\%). Triggers pointing at deficient quality of care were found in $78 \%$ of the records, with the absence of a treatment plan being the most common.
\end{abstract}

Conclusions: AEs are common in psychiatric care. Aside from further patient safety work, systematic interventions are also warranted to improve the quality of psychiatric care.

Keywords: Adverse event, Patient harm, Patient safety, Trigger tool, Psychiatry

\section{Background}

In the last few decades, there has been a growing interest in patient safety worldwide, with the vast majority of research focusing on somatic healthcare. Although many patient safety risk factors in somatic settings also apply to psychiatric and mental health care, recognising specific adverse events (AEs) that are unique to mental healthcare is

\footnotetext{
* Correspondence: lena.nilsson@regionostergotland.se

${ }^{1}$ Department of Anaesthesiology and Intensive Care, Department of

Biomedical and Clinical Sciences, Linköping University, Linköping, Sweden

${ }^{2}$ Department of Anaesthesiology and Intensive Care, University Hospital, 583

81 Linköping, Sweden

Full list of author information is available at the end of the article
}

important. Examples of these AEs are those regarding seclusion and use of restraint, self-harm and suicidal behaviour. Some of these events have been investigated, such as suicide and self-harm [1-5], medication errors [6, 7] and seclusion and restraint $[8,9]$, but the overall level and nature of AEs within psychiatry have been sparsely explored [10-12].

The retrospective medical record review is an established and validated method to identify AEs in healthcare [13-15]. A list of criteria (triggers) is commonly used to identify details in the records that often are associated with the presence of AEs. The trigger tool methodology gives information on the incidence, nature,

(c) The Author(s). 2020 Open Access This article is distributed under the terms of the Creative Commons Attribution 4.0 International License (http://creativecommons.org/licenses/by/4.0/), which permits unrestricted use, distribution, and reproduction in any medium, provided you give appropriate credit to the original author(s) and the source, provide a link to the Creative Commons license, and indicate if changes were made. The Creative Commons Public Domain Dedication waiver (http://creativecommons.org/publicdomain/zero/1.0/) applies to the data made available in this article, unless otherwise stated. 
preventability and consequences of AEs that can be used in systematic quality improvement work.

Most studies on the patient safety trigger tool have been undertaken in adult hospital somatic care. In Sweden, the trigger tool methodology has been used for somatic care at a national level since 2012 [16, 17].

The IHI Global Trigger Tool [18] has been used since 2008. Trigger tools have also been adapted for specific areas, such as paediatric care $[19,20]$, primary care [21] and home healthcare [22]. In mental health services there is a trigger tool for measuring adverse drug events [23], and a combined trigger tool for detecting somatic AEs and mental health-related patient safety incidents [12].

In Sweden patients with less severe mental disorders, primarily anxiety and depression, are primarily taken care of in the primary care system by a general practicioner (mental health services), while patients having more severe conditions are referred to psychiatric departments for hospital or outpatient care. In this study we focused on the latter adult patient population.

This study aimed 1) to develop a national trigger tool for adult psychiatric care and 2) to describe the incidence, nature, preventability and severity of AEs in adult psychiatric healthcare.

\section{Methods}

Development and implementation of the Swedish national psychiatric trigger tool

The IHI Global Trigger Tool [18] has been used in Swedish healthcare since 2008. Following a national patient safety initiative (2011-2014), all acute care hospitals have their own somatic review teams, and a national database was developed by the Swedish Association of Local Authorities and Regions.

In 2012, the representatives of psychiatric healthcare and the mental health patient organisations started developing a psychiatric trigger tool. Together, the risk areas specific to psychiatric hospital care were identified such as coercion, suicide risk assessment, medication, threats and violence, non-compliance to treatment plan, transitions in healthcare and the diagnostic process. An AE was defined as suffering, a physical or psychological unfavourable event or disease or death as a result of the contact between a patient and healthcare. An AE was categorised into one of 22 different types (Table 1). Each $\mathrm{AE}$ could only be categorised into one specific type.

Much effort was put into developing guidelines on how to define an AE. A patient perspective was considered by reviewing hospital care and the corresponding

Table 1 Area and type of AEs

\begin{tabular}{|c|c|c|}
\hline Area of $\mathrm{AE}$ & Type of AE & Examples \\
\hline \multirow[t]{2}{*}{ Mental injury } & 1. Suffering & Insecurity, fear after threat/violence, discomfort, stigmatisation \\
\hline & 2. Insult & In connection with coercive measures, sexual abuse \\
\hline \multirow[t]{4}{*}{ Prolonged disease progression } & 3. Untreated condition & \multirow{7}{*}{$\begin{array}{l}\text { Incomplete investigation with incorrect diagnosis } \\
\text { Unwanted effect in psychotherapy } \\
\text { Insufficient assessment during ongoing treatment }\end{array}$} \\
\hline & 4. Insufficient effect of treatment & \\
\hline & 5. Interrupted treatment & \\
\hline & 6. Disease worsening & \\
\hline \multirow[t]{3}{*}{ Deliberate self-harm } & 7. Suicide & \\
\hline & 8. Suicide attempt & \\
\hline & 9. Self-harm without suicidal intent & \\
\hline \multirow[t]{5}{*}{ Medication-related injury } & 10. Metabolic influence & \multirow{5}{*}{$\begin{array}{l}\text { Acute dystonia, dyskinesia, akathisia, affected renal function, confusion, } \\
\text { sedation, hypotonia, malignant neuroleptic syndrome, serotonin syndrome, } \\
\text { medication error }\end{array}$} \\
\hline & 11. Extrapyramidal symptoms & \\
\hline & 12. Allergic reaction & \\
\hline & 13. Drug addiction & \\
\hline & 14. Other drug-related harm & \\
\hline \multirow[t]{2}{*}{ Illegal/unethical treatment } & 15. Illegal restraint & \multirow[t]{2}{*}{ Detained after administrative mishaps } \\
\hline & 16. Measures without support in law & \\
\hline \multirow[t]{5}{*}{ Physical injury } & 17. Anaesthesia-related injury & \multirow{5}{*}{$\begin{array}{l}\text { Tooth damage, breathing and/or circulation failure, fracture, haemorrhage, } \\
\text { infection, memory disorder after electroconvulsive therapy }\end{array}$} \\
\hline & 18. Falls & \\
\hline & 19. Pressure ulcer category $2-4$ & \\
\hline & 20. Cognitive failure & \\
\hline & 21. Other physical harm & \\
\hline Others & 22. Other AEs & \\
\hline
\end{tabular}


outpatient care as a continuum for each patient. In contrast to somatic care in which only hospital care has been reviewed when the trigger tool review method is used, we assessed all documented care during a threemonth period for each medical record.

Based on the identified risk areas and known types of AEs, triggers with the possibility of identifying harm were formulated. AEs were categorised into one of four severity categories: Less-discomfort or insignificant harm, Moderate-temporary disability, Significant-permanent disability and Catastrophic-permanent substantial disability, death.

An $\mathrm{AE}$ was categorised as preventable or not by using a graded scale of four options: 1) 'not preventable', 2) 'probably not preventable', 3) 'probably preventable' and 4) 'certainly preventable'. AEs resulting from omission were regarded as preventable. The manual gave detailed instructions on the difficult assessment of preventability (Table 2). AEs classified as categories 1 and 2 are denoted as non-preventable, and AEs labelled as 3 and 4 as preventable in the following text and tables.

The trigger tool underwent a pilot test of 471 records from 17 of the 21 regions in the country. The final version was completed in 2015. Divided into 5 modules, namely, treatment, drugs, coercive treatment, medicine and continuity and transition, 36 triggers were described (Table 3). Since 2015, centralised education has been offered regularly to new members in the 'review teams' in psychiatric healthcare.

\section{Inclusion criteria and sampling}

Randomly selected records of patients aged 18 years or older who had been discharged from psychiatric hospital care between January 1, 2017 and June 30, 2017 were reviewed. Each record was assessed for a three-month period. Both hospital stays and associated outpatient care were included in the assessment, which was

Table 2 Example of preventability assessment instructions

\begin{tabular}{ll}
\hline T1 Coercion treatment-administrative failure \\
\hline Definition & $\begin{array}{l}\text { Failure in the documentation of decisions according } \\
\text { to LPT or LRV or Time limits given for coercion were } \\
\text { not followed or documented correctly. }\end{array}$ \\
To remember & $\begin{array}{l}\text { The violation of rules may lead to the patient being } \\
\text { custodial without legal support or not having his/her } \\
\text { rights catered for, e.g., information and the possibility } \\
\text { to appeal against coercion decisions. }\end{array}$ \\
& $\begin{array}{l}\text { Is the documentation of decisions adequate? } \\
\text { AE that can be }\end{array}$ \\
found & $\begin{array}{l}\text { The patient is exposed to authority handling without } \\
\text { legal support, custodial and psychic suffering. }\end{array}$ \\
& $\begin{array}{l}\text { If time limits were not followed in connection with } \\
\text { coercion or if the documentation of coercion is } \\
\text { incorrect, the AE is considered preventable. }\end{array}$
\end{tabular}

AE: Adverse event; LPT, LRV: Swedish laws of coercion in psychiatric and forensic healthcare discontinued at a minimum of 30 days before the time for review to enable the identification of AEs not obvious until after discharge. All 21 regions in Sweden participated in the study.

\section{Review process}

Each hospital had its own review team that consisted of one or two nurses or other mental healthcare professionals with long experience and at least one physician. All team members were senior level with special training in the record review method and an interest and knowledge in the field of patient safety.

The process started with a nurse or a mental healthcare professional screening the records for the presence of triggers and possible AEs. The full record including observational notes, medication charts, laboratory tests etc. was examined. The second review stage had a dual purpose: 1) The team assessed the occurrence of AEs, which were categorised according to type, severity and preventability. 2) The identification of triggers was used to assess quality of care, including level of compliance to local guidelines and clinical routines, regardless of the occurrence of an AE. Nineteen of the 36 triggers could be used for determining the lack of quality. Examples of such triggers were 'absence of care plan', 'absence of family contact', 'lack of suicide risk assessment' and 'lack of documented physical observations' in connection with inpatient care. There was no time limit for the review stages. No assessment of interrater reliability was performed.

\section{Statistics}

Data are presented as the number (percent), median (range) or mean [95\% confidence interval (CI)]. Comparison of the proportions was made using a chisquared test. We calculated the CIs using a normal distribution approximation. A $p$ value of less than 0.05 was considered significant. All statistical calculations were made using SPSS version 25 (IBM, New York, USA).

\section{Results}

In total, 2552 medical records were reviewed. This number corresponded to $3 \%$ of the national psychiatric hospital care during a six-month period and was divided by the regions in proportion to the total number of hospital stays. The distribution between sexes was equal, with $50.4 \%$ women and $49.6 \%$ men. The median (range) age was 44 (18-97) years for women and 44.5 (18-93) years for men. A total of 707 (28\%) of the records included hospital care only, and the rest covered hospital and outpatient care.

Out of the 2552 records reviewed, 438 (17.2\%, 95\% CI 15.7-18.6) records had a total of 720 identified AEs. Among the reviewed records, 8.0\% (95\% CI 7.0-9.1) had AEs that were classified as preventable. In total, $46,2 \%$ of 
Table 3 The final trigger tool

\begin{tabular}{|c|c|}
\hline \multicolumn{2}{|c|}{ Treatment } \\
\hline V1 & Absence of a care plan \\
\hline V2 & Absence of an intervention plan \\
\hline V3 & Lack of suicide risk assessment \\
\hline V4 & Lack of review of crime relapse risks \\
\hline V5 & Falls \\
\hline V6 & Documentation of failure \\
\hline V7 & $\begin{array}{l}\text { Consultation with a physician on call/doctor from } \\
\text { another specialty }\end{array}$ \\
\hline V8 & Change in diagnosis \\
\hline V9 & Self-harm \\
\hline V10 & Undesired effect of treatment other than medication \\
\hline V11 & Threats, violence and inappropriate behaviour \\
\hline $\mathrm{V} 12$ & Increased surveillance \\
\hline V13 & Lack of documented physical observations \\
\hline V14 & Absence of family contact \\
\hline V15 & Others \\
\hline \multicolumn{2}{|l|}{ Drugs } \\
\hline $\mathrm{Y} 1$ & Absence of the alcohol use disorder identification test (AUDIT) \\
\hline Y2 & Absence of the addiction severity index (ASI) \\
\hline Y3 & Absence of the expiratory alcohol test \\
\hline Y4 & Absence of a urinary lab test when addiction is suspected \\
\hline \multicolumn{2}{|c|}{ Coercive treatment } \\
\hline $\mathrm{T} 1$ & Coercion treatment-administrative failure \\
\hline $\mathrm{T} 2$ & Coercion \\
\hline $\mathrm{T} 3$ & $\begin{array}{l}\text { Conversion from voluntary treatment to coercion } \\
\text { (emergency law) }\end{array}$ \\
\hline $\mathrm{T} 4$ & Police assistance \\
\hline \multicolumn{2}{|c|}{ Medicine } \\
\hline B1 & Use of three or more different antipsychotic drugs \\
\hline B2 & Treatment with anticholinergics \\
\hline B3 & Use of more than five different psychotropic drugs \\
\hline B4 & $\begin{array}{l}\text { More than three benzodiazepines or treatment for more } \\
\text { than } 6 \text { months }\end{array}$ \\
\hline B5 & $\begin{array}{l}\text { Faults in screening for metabolic risk factors during } \\
\text { antipsychotic treatment }\end{array}$ \\
\hline B6 & $\begin{array}{l}\text { Lack of regular tests for medication with lithium, } \\
\text { methylphenidate, methadone/buprenorphine or clozapine }\end{array}$ \\
\hline B7 & Medication, others \\
\hline \multicolumn{2}{|c|}{ Continuity and transition } \\
\hline
\end{tabular}

R1 Unplanned contact with a psychiatric acute unit
Table 3 The final trigger tool (Continued)

\begin{tabular}{ll} 
R2 & Reinstatement within 30 days \\
R3 & Change in treatment unit \\
R4 & Unplanned discharge \\
R5 & Lack of doctors' visit during the last 12 months in \\
& outpatient care \\
R6 & Lack of an accountable primary physician \\
\hline
\end{tabular}

the identified AEs were assessed as preventable. No significant difference was found in the incidence of AEs among the different age groups.

The AEs mostly resulted in less or moderate harm: less harm (discomfort, insignificant harm) accounted for 41.0\%; moderate harm (transient disability) accounted for $46.1 \%$, severe harm (permanent moderate disability) accounted for $12.5 \%$ and catastrophic harm (permanent major disability, death) accounted for $0.4 \%$. Prolonged disease progression and deliberate self-harm were the most common types of AEs. The identified types of AEs differed between hospital and outpatient care (Table 4).

AEs were significantly more common in women $(21.5 \%)$ than in men $(12.7 \%)(p<0.001)$. A significant gender difference was also seen for preventable AEs at $9.7 \%$ for women and $6.3 \%$ for men $(p=0.002)$. The most prominent difference was found in the category deliberate self-harm, with an incidence of $7.5 \%$ in women and $2.0 \%$ in men (Fig. 1). A significant gender difference in the total material remained after the removal of this category.

A detailed description of the areas and types of AEs is shown in Table 5. 'Prolonged disease progression' was the most common $\mathrm{AE}$ area. Among the specific $\mathrm{AE}$ types, 'disease worsening' was the most prominent. From a patient perspective, coercive measures, such as the manual or mechanical restraint of the patient's limbs or body to prevent free movement, are a violation. Thus, we regarded this measure as an AE. Such AEs may be preventable depending on the situation. This was assessed by the review teams.

Triggers pointing at deficient quality of care were found in 1995 (78\%, 95\% CI 76.5-79.8\%) of the records. The most common triggers were 'absence of care plan', 'absence of family contact', 'lack of suicide risk assessment' and 'lack of documented physical observations' related to inpatient care (Table 6). More than one type of trigger indicating deficient care quality was usually found during a single care episode.

The proportion of patients with less or moderate harm was $15.9 \%$ and severe or catastrophic harm $2.3 \%$. The different areas of AEs, gender and the degree of preventability of the severe or catastrophic AEs are displayed in Table 7. Thirty-six (61\%) of the patients with severe or catastrophic harm were women and 23 (39\%) were men. 
Table 4 AEs in psychiatric care

\begin{tabular}{|c|c|c|c|c|}
\hline Area of $A E$ & Total number of AEs $n(\%)$ & Preventable AEs n (\%) & AEs in hospital care $\mathrm{n}(\%)$ & AEs in outpatient care $\mathrm{n}(\%$ \\
\hline Prolonged disease progression & $214(30)$ & $148(69)$ & $102(23)$ & $112(41)$ \\
\hline Deliberate self-harm ${ }^{a}$ & $177(25)$ & $42(24)$ & $106(24)$ & $71(26)$ \\
\hline Mental injury & $139(19)$ & $68(49)$ & $106(24)$ & $33(12)$ \\
\hline Medication-related injury & $84(12)$ & $27(32)$ & $52(12)$ & $32(12)$ \\
\hline Physical injury & $68(9)$ & $21(31)$ & $60(13)$ & $8(3)$ \\
\hline Other & $33(4)$ & $24(73)$ & $18(4)$ & $15(6)$ \\
\hline Illegal/unethical treatment & $5(1)$ & $3(60)$ & $5(1)$ & $0(0)$ \\
\hline Total & $720(100)$ & $333(46)$ & $449(100)$ & $271(100)$ \\
\hline
\end{tabular}

${ }^{a}$ Among the AEs in the area of deliberate self-harm, the AE type suicide attempt was significantly more common in outpatient care, and the incidence of deliberate self-harm did not differ between patients in hospital care and those in outpatient care

$A E$ Adverse event

The distribution in age less than or 45 years and older was equal (32 and 27 patients, respectively), as was the distribution between hospital and outpatient care (31 and 35 patients, respectively).

\section{Discussion}

To the best of our knowledge, this study is the first multicentric, national study to report on psychiatric AEs at a national level. AEs occurred in $17 \%$ of the investigated care episodes, mostly resulting in less or moderate harm and with almost half considered as preventable. Women were more affected than men, but no difference was found among the different age groups. Prolonged disease progression was the most common $\mathrm{AE}$, followed by deliberate self-harm and mental injury.

There are few retrospective record reviews based on a trigger tool approach with which to compare our results. Marcus et al. [10] investigated 8000 psychiatric hospitalisations in the United States and found a prevalence of
$28 \%$ of patient safety events, including events with potentially negative consequences and adverse drug events, which were by far the most frequent (6\%). Only $19 \%$ of AEs were considered preventable in this study, and almost $85 \%$ resulted in no or minor harm. In a recent publication from Singapore, 11\% of the reviewed records had at least one mental healthcare-associated patient safety incident, and most of the events were aggressive behaviours [12]. In the same study, an AE of any kind was found in $19 \%$ of the patient records.

In comparison to somatic hospital healthcare with increasing frequencies of AEs with age [16], the equal distribution of AEs in different age groups is striking. In the present study, only $15 \%$ of the patients were 65 years or older. The corresponding figure for the Swedish somatic hospital healthcare was $66 \%$ [16]. One possible explanation for this difference in age distribution in somatic and psychiatric hospital care is that mental diseases usually have an earlier onset than somatic diseases.

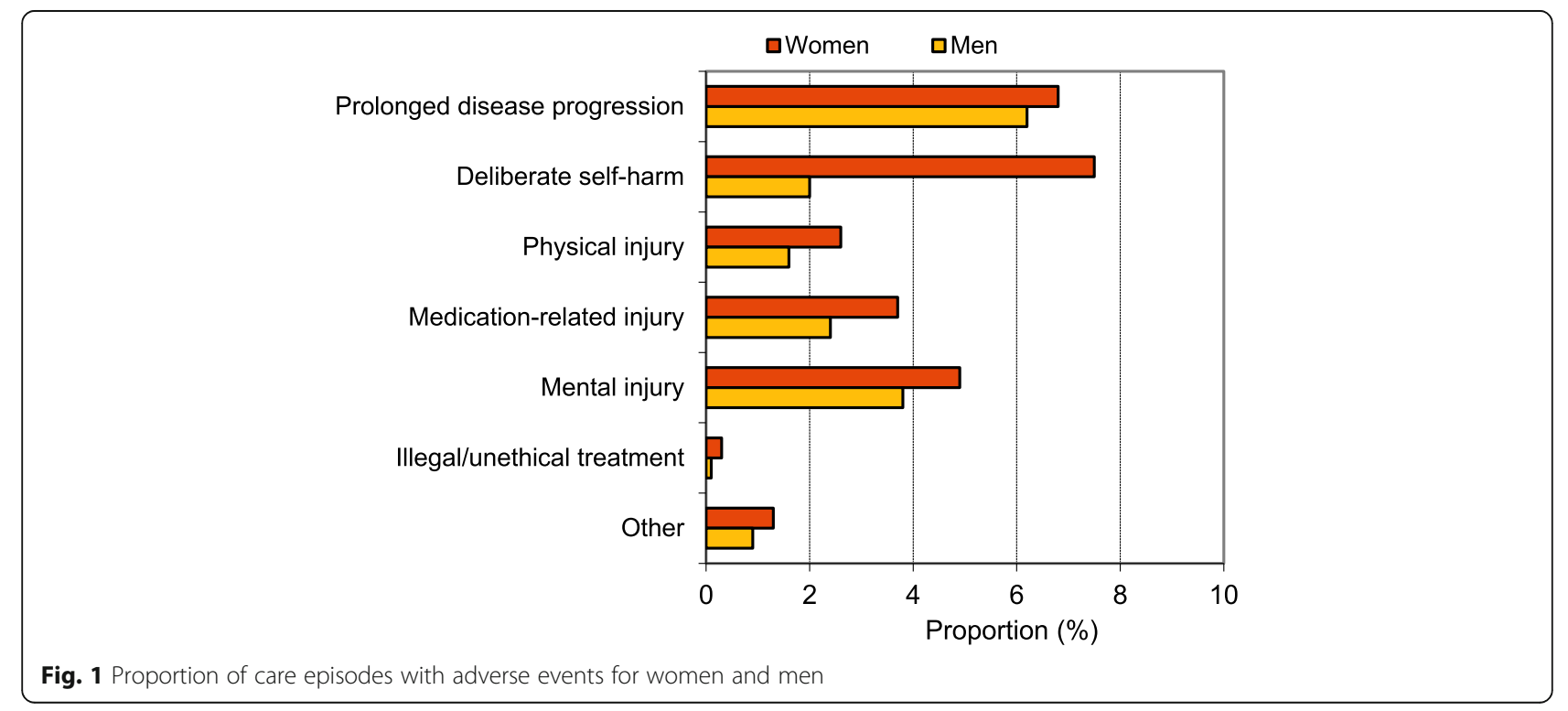


Table $\mathbf{5}$ Incidence of AEs categorised according to area and type

\begin{tabular}{|c|c|c|}
\hline Area and type of AE & Incidence (\%) & \\
\hline Mental injury & 4.3 & \\
\hline Suffering & & 3.5 \\
\hline Insult & & 1.3 \\
\hline Prolonged disease progression & 6.5 & \\
\hline Untreated condition & & 1.5 \\
\hline Insufficient effect of treatment & & 2.3 \\
\hline Interrupted treatment & & 0.9 \\
\hline Disease worsening & & 3.0 \\
\hline Deliberate self-harm & 4.8 & \\
\hline Suicide & & 0.0 \\
\hline Suicide attempt & & 2.2 \\
\hline Self-harm without suicidal intent & & 3.1 \\
\hline Medication-related injury & 3.1 & \\
\hline Metabolic influence & & 0.5 \\
\hline Extrapyramidal symptoms & & 0.6 \\
\hline Allergic reaction & & 0.2 \\
\hline Drug addiction & & 0.3 \\
\hline Other drug-related harm & & 1.6 \\
\hline Illegal/unethical treatment & 0.2 & \\
\hline Illegal restraint & & 0.1 \\
\hline Measures without support in law & & 0.1 \\
\hline Physical injury & 2.1 & \\
\hline Anaesthesia-related injury & & 0.0 \\
\hline Falls & & 1.1 \\
\hline Pressure ulcers category $2-4$ & & 0.0 \\
\hline Cognitive failure & & 0.2 \\
\hline Other physical harm & & 0.9 \\
\hline Other & 1.1 & \\
\hline
\end{tabular}

$A E$ Adverse event

Another explanation is that older patients with concurrent mental and somatic diseases are usually cared for in somatic healthcare only and not captured in this study. A Swedish report from the National Board of Health and Welfare found that death was more common one year after admission in a somatic department for the treatment of depression, schizophrenia and abuse than if the treatment had been given in a department specialising in psychiatric care [24]. There were also less use of psychotropic drugs and fewer new admissions to inhospital mental care after somatic physicians' surveillance of the patients. This finding could indicate that psychiatric diseases were not taken care of in an optimal way in somatic departments. An epidemiological Danish study showed that psychiatric treatment in the preceding year was associated with an increased risk of dying from suicide [25], underlining the complexity of care for mental disorders.

Pharmacotherapy plays an important role in mental health treatment, and patients with serious psychiatric conditions can be vulnerable to risks and side effects associated with the treatment, such as cognitive impairment. This situation may affect the poor reporting of medication-related AEs. Different psychotropics can contribute to somatic health problems, such as impaired glucose tolerance and extrapyramidal side effects. Polypharmacy is common, thus increasing this risk. A systematic review [26] found that adverse drug events occurred in 10-42 per 1000 patient days in mental health hospitals, with psychotropic medication accounting for the majority of harmful events. In the present study, we found that $12 \%$ of the AEs were medication related. It is difficult to compare studies as several factors differ: health care systems; diagnostic panoramas; data sampling from trigger tools, incident reports, pharmacy or nurse staff reports; and data presentation. Still, our rate seem low and might be underreported. Approximately one-third of the medication-related AEs were considered avoidable. This result can be compared with the American Psychiatric Association's action for patient safety [27], which estimated that half of drugrelated AEs could have been prevented. Non-psychiatric drugs are associated with preventable AEs more often than psychiatric drugs [28, 29].

The majority of AEs as well as AEs causing severe or catastrophic harm affected women and for the latter group it was seen in all areas of AEs. This was a surprising finding and something that differs from what is known from somatic care [16]. Although sex differences have been observed across many psychiatric diseases [30], our cohort had equally distributed sex. We have not found other studies reporting on gender differences for AEs. In our study we did not investigate courses of harm. Our finding implies that preventive measures for women should be focused in clinical practice and further studies.

In our study, AEs were more common in hospital care than in out-patient care. This finding was expected, as care in hospitals is ongoing round the clock, patients are more severely ill and more advanced care is usually given. This condition contributes to an increased risk for AEs. However, the AE area 'prolonged disease progression' was the most common in out-patient care and more common than that in hospital care. This result can indicate low accessibility to and/or flexibility in outpatient care. It can also be explained by poor cooperation with the patient's relatives. According to a recent report of the Swedish Health and Social Care Inspectorate (IVO), both patients and relatives have sparse influence on care planning [31]. Another difference between 
Table 6 Incidence of care episodes with triggers pointing at deficient quality of care

\begin{tabular}{|c|c|}
\hline Trigger & Number (Percent) \\
\hline \multicolumn{2}{|l|}{ Treatment } \\
\hline Absence of care plan & $926(36.3)$ \\
\hline Lack of documented physical observations & $582(22.8)$ \\
\hline Lack of suicide risk assessment & $401(15.7)$ \\
\hline Absence of family contact & $272(10.7)$ \\
\hline Absence of intervention plan & $235(9.2)$ \\
\hline Lack of review of crime relapse risk & $19(0.7)$ \\
\hline \multicolumn{2}{|l|}{ Drugs } \\
\hline Absence of the alcohol use disorder identification test (AUDIT) & $319(12.5)$ \\
\hline Absence of a urinary lab test when addiction is suspected & $218(8.5)$ \\
\hline Absence of the expiratory alcohol test & $107(4.2)$ \\
\hline Absence of the addiction severity index (ASIA) & $50(2.0)$ \\
\hline \multicolumn{2}{|l|}{ Coercive treatment } \\
\hline Coercion treatment-administrative failure & $76(3.0)$ \\
\hline \multicolumn{2}{|l|}{ Medicine } \\
\hline Use of more than five different psychotropic drugs & $251(10.1)$ \\
\hline More than three benzodiazepines or treatment for more than 6 months & $247(9.7)$ \\
\hline Faults in screening for metabolic risk factors during antipsychotic treatment & $202(7.9)$ \\
\hline Lack of regular tests for medication with lithium, methylphenidate, methadone/buprenorphine or clozapine & $187(7.3)$ \\
\hline Use of three or more different antipsychotic drugs & $75(2.9)$ \\
\hline \multicolumn{2}{|l|}{ Continuity and transition } \\
\hline Lack of an accountable physician & $367(14.4)$ \\
\hline Unplanned discharge & $268(10.5)$ \\
\hline Lack of physician's visit during the last 12 months in outpatient care & $69(2.7)$ \\
\hline
\end{tabular}

outpatient and hospital care becomes obvious when the incidence of attempted suicide is considered. Hospital care seems to provide the suicide preventative effect that is intended by hospitalisation. However, unfortunately, the same benefit is not seen in deliberate self-harm, the incidence of which is not reduced to the same extent.

As mental AEs affect young people of working age, the common AE 'prolonged disease progression' might have considerable economic consequences to society and to the affected individual.
The number of AEs in the area of 'illegal/unethical treatment' is very low in our study at $1 \%$. Only $60 \%$ of these AEs were regarded as preventable. From a legal point of view, all AEs in this category should be preventable because they are against the law by definition. However, in an acute situation in which coercive measures were found necessary, the review teams might have chosen to consider the $\mathrm{AE}$ as not preventable.

The unexpectedly high frequency of triggers (78\% of the records) indicating deficiency in the overall quality

Table 7 Incidence of severe and catastrophic AEs categoridsed according to area, gender and preventability

\begin{tabular}{llll}
\hline Area of AE & Severe and catastrophic AEs $n(\%)$ & Men/women $n$ & Preventable AE $n(\%)$ \\
\hline Prolonged disease progression & $44(20.6)$ & $18 / 26$ & $38(86.4)$ \\
Deliberate self-harm & $18(10.2)$ & $8 / 10$ & $10(55.6)$ \\
Mental injury & $12(8.6)$ & $3 / 9$ & $11(91.7)$ \\
Medication-related injury & $11(13.1)$ & $4 / 7$ & $5(45.5)$ \\
Physical injury & $2(2.9)$ & $0 / 2$ & $0(0)$ \\
Other & $6(18.2)$ & $2 / 4$ & $3(50.0)$ \\
Illegal/unethical treatment & $0(0)$ & $0 / 0$ & $0(0)$ \\
Total & $93(12.9)$ & $35 / 58$ & $67(72.0)$
\end{tabular}

$A E$ Adverse event 
of care can have several explanations. The patient safety movement started in somatic healthcare and reached mental health services and psychiatric care at a later stage. In a national Swedish survey, the patient safety culture was rated lower than in somatic care [32]. The lack of documentation of physical status during psychiatric hospital care is troublesome, as patients with a serious mental illness have higher rates of physical conditions, such as obesity, diabetes, hypertension and HIV/AIDS [33, 34], and risk behaviour, such as smoking, drinking alcohol and physical inactivity [35].

Our study has several strengths. The review was undertaken on a national basis. No specific trigger tool was at hand, but there was profound experience in the research group from the development and national use of a trigger tool for somatic care. Our triggers and description of psychiatric AEs were formed after discussions in a national expert panel, patient organisations and round-table discussions. A preliminary version of the trigger tool was adjusted according to the testing results. The review teams were given centralised education, and support was available all throughout to synchronise the review process. This study is limited by the retrospective design with the risk of hindsight bias and the risk of information bias, as only what had been documented in the records could be assessed. No assessment of interrater reliability was conducted. It can sometimes be difficult to decide if a gradual worsening of a disease is due to deviation from standard care and thus regarded as an $\mathrm{AE}$ or the natural course in spite of correct treatment. Included causes for classification as AEs were for instance incomplete investigation, incorrect diagnosis or treatment inadequate or delayed leading to worsening of disease. Although thoroughly discussed during the second review stage, it remains a subjective decision.

\section{Conclusions}

A trigger tool for the assessment of AEs in psychiatric care was developed and found useful. AEs seemed to be as common in mental as in somatic healthcare, but the majority of AEs resulted in minor or less harm. In contrast to somatic care, no differences were found in age in psychiatric care. This study provides further knowledge in the area of AEs in psychiatric care. As almost half of the identified AEs were assessed as preventable, there are clear indications for areas where efforts for improvement of patient safety could be intensified. Systematic interventions to improve the quality of psychiatric care are warranted.

\section{Abbreviations}

AE: Adverse event; Cl: Confidence interval; IVO: Swedish Health and Social Care Inspectorate

\section{Acknowledgments}

The authors are grateful for the contributions of all the review teams.

\section{Authors' contributions}

$L N, M B-R, C B, U N 1, U N 2, C \AA$ and $H R$ designed and conducted the study. MB-R statistically analysed the data. HR, UN2 and CA undertook the initial interpretation of the data, which was discussed with all the authors. LN and HR drafted the initial version of the manuscript, which was followed by a critical revision process of the intellectual content involving all the authors. All the authors agreed to the final version of the manuscript before submission. All authors read and approved the final manuscript.

\section{Funding}

This work was supported by the Swedish Association of Local Authorities and Regions by creating and hosting a national database for the reporting of data from the record reviews. The funding body did not influence the study design, collection of data, analysis, interpretation of data or writing the manuscript. Open access funding provided by Linköping University.

\section{Availability of data and materials}

Data are available from the authors upon reasonable request and with permission of the Swedish Association of Local Authorities and Regions.

Ethics approval and consent to participate

The study was conducted in compliance with the Declaration of Helsinki (World Medical Association 2013). As it was part of quality improvement initiatives in the hospitals, an approval from an ethical committee was not necessary. The principles published in the national ethical guidelines for research were followed (SFS 2003:460)

As the record review was part of the quality improvement initiatives in the hospitals, consent from the patients was not necessary. Names and personal identification numbers were not collected or entered into the database.

\section{Consent for publication}

Not applicable.

\section{Competing interests}

The authors declare that they have no competing interests.

\section{Author details}

'Department of Anaesthesiology and Intensive Care, Department of Biomedical and Clinical Sciences, Linköping University, Linköping, Sweden. ${ }^{2}$ Department of Anaesthesiology and Intensive Care, University Hospital, 583 81 Linköping, Sweden. ${ }^{3}$ Centre for Organisational Support and Development (CVU), Region Östergötland, Linköping University, Linköping, Sweden. ${ }^{4}$ Department of Psychiatry, Kalmar County Council, Kalmar, Sweden. ${ }^{5}$ Stockholm Centre for Psychiatric Research and Education, Department of Clinical Neuroscience, Karolinska Institutet, Stockholm, Sweden. ${ }^{6}$ National Board of Health and Welfare, Stockholm, Sweden. ${ }^{7}$ Swedish Association of Local Authorities and Regions, Stockholm, Sweden.

Received: 5 June 2019 Accepted: 21 January 2020

Published online: 04 February 2020

\section{References}

1. Goh SE, Salmons PH, Whittington RM. Hospital suicides: are there preventable factors? Profile of the psychiatric hospital suicide. $\mathrm{Br} J$ Psychiatry. 1989:154:247-9.

2. Gray NS, Hill C, McGleish A, Timmons D, MacCulloch MJ, Snowden RJ. Prediction of violence and self-harm in mentally disordered offenders: a prospective study of the efficacy of HCR-20, PCL-R, and psychiatric symptomatology. J Consult Clin Psychol. 2003;71:443-51.

3. Powell J, Geddes J, Hawton K, Deeks J, Goldacre M. Suicide in psychiatric hospital in-patients. Br J Psychiatry. 2000;176:266-72.

4. Mills PD, King LA, Watts BV, Hemphill RR. Inpatient suicide on mental health units in veterans affairs (VA) hospitals: avoiding environmental hazards. Gen Hosp Psychiatry. 2013:35:528-36.

5. Watts BV, Shiner B, Young-Xu Y, Mills PD. Sustained effectiveness of the mental health environment of care checklist to decrease inpatient suicide. Psychiatr Serv. 2017 Apr 1;68:405-7. 
6. Grasso BC, Genest R, Jordan CW, Bates DW. Use of chart and record reviews to detect medication errors in a state psychiatric hospital. Psychiatr Serv. 2003;54:677-81.

7. Grasso BC, Rothschild JM, Genest R, Bates DW. What do we know about medication errors in inpatient psychiatry? Jt Commi J Qual Saf. 2003;29:391400.

8. Mohr WK, Petti TA, Mohr BD. Adverse effects associated with physical restraint. Can J Psychiatr. 2003;48:330-7.

9. Crenshaw WB, Francis PS. A national survey on seclusion and restraint in state psychiatric hospitals. Psychiatr Serv. 1995;46:1026-31.

10. Marcus SC, Hermann RC, Frankel MR, Cullen SW. Safety of psychiatric inpatients at the veterans health administration. Psychiatr Serv. 2018;69:20410.

11. Shields MC, Stewart MT, Delaney KR. Patient safety in inpatient psychiatry: a remaining frontier for health policy. Health Aff (Millwood). 2018;37:1853-61.

12. Sajith SG, Fung D, Chua HC. The mental health trigger tool: development and testing of a specialized trigger tool for mental health settings. J Patient Saf. 2019 Apr 18. https://doi.org/10.1097/PTS.0000000000000606 [Epub ahead of print].

13. Naessens JM, Campbell CR, Huddleston JM, Berg BP, Lefante JJ, Williams AR, et al. A comparison of hospital adverse events identified by three widely used detection methods. Int J Qual Health Care. 2009;21:301-7.

14. Christiaans-Dingelhoff I, Smits M, Zwaan L, Lubberding S, van der Wal G, Wagner $C$. To what extent are adverse events found in patient records reported by patients and healthcare professionals via complaints, claims and incident reports? BMC Health Serv Res. 2011;11:49.

15. Classen DC, Resar R, Griffin F, Federico F, Frankel T, Kimmel N, et al. "globa trigger tool" shows that adverse events in hospitals may be ten times greater than previously measured. Health Aff. 2011;30:581-9.

16. Nilsson L, Borgstedt-Risberg M, Soop M, Nylén U, Ålenius C, Rutberg H. Incidence of adverse events in Sweden during 2013-2016: a cohort study describing the implementation of a national trigger tool. BMJ Open. 2018;8: e020833.

17. Nilsson L, Borgstedt Risberg M, Montgomery A, Sjödahl R, Schildmeijer K, Rutberg H. Preventable adverse events in surgical care in Sweden. A nationwide review of patient notes. Medicine (Baltimore). 2016;95:e3047.

18. Griffin FA, Resar RK. IHI global trigger tool for measuring adverse events. $|H|$ innovation series white paper. Cambridge, Massachusetts: Institute for Healthcare Improvement; 2007.

19. Matlow AG, Cronin CM, Flintoft V, Nijssen-Jordan C, Fleming M, Brady-Fryer $B$, et al. Description of the development and validation of the Canadian Paediatric trigger tool. BMJ Qual Saf. 2011;20:416-23.

20. Unbeck M, Lindemalm S, Nydert P, Ygge BM, Nylén U, Berglund C. Härenstam KP validation of triggers and development of a pediatric trigger tool to identify adverse events. BMC Health Serv Res. 2014;14:655.

21. De Wet C, Bowie P. Screening electronic patient records to detect preventable harm: a trigger tool for primary care. Qual Prim Care. 2011;19: $115-25$.

22. Schildmeijer K, Unbeck M, Ekstedt M, Lindblad M, Nilsson L. Adverse events in patients in home healthcare: a retrospective record review using trigger tool methodology. BMJ Open. 2018;3;8:e019267.

23. Trigger Tool for Measuring Adverse Drug Events in a Mental Health Setting. Institute for Healthcare Improvement (in collaboration with Noeleen Devaney, Director, Northern Ireland CSCG Support Team) Cambridge, Massachusetts, USA http://www.ihi.org/resources/Pages/Tools/ TriggerToolMeasuringADEsinMentalHealthSetting.aspx Accessed 2018-09-28

24. [Psychiatric disease among elderly and treatment in helathcare.] In Swedish. 2013 https://www.socialstyrelsen.se/globalassets/sharepoint-dokument/ artikelkatalog/ovrigt/2013-6-22.pdf Accessed Dec 052019

25. Hjorthøj CR, Madsen T, Agerbo E, Nordentoft M. Risk of suicide according to level of psychiatric treatment: a nationwide nested case-control study. Soc Psychiatry Psychiatr Epidemiol. 2014;49:1357-65.

26. Alsheri GH, Keers RN, Ashcroft DM. Frequency and nature of medication errors and adverse drug events in mental health hospitals: a systematic review. Drug Saf. 2017;40:871-86.

27. Patient safety and psychiatry recommendations to the Board of Trustees of the American Psychiatric Association. Approved by the Board of Trustees November 24, 2002 and by the Assembly Executive Committee January 24 2003 https://www.google.se/url?sa=t\&rct=j\&q=\&esrc=s\&source=web\&cd= $1 \&$ cad=rja\&uact=8\&ved=2ahUKEwitjaDXoZPgAhXGplsKHW_ cDGMQFjAAegQIBRAC\&url=https\%3A\%2F\%2Fwww.psychiatry.org\%2
FFile\%2520Library\%2FPsychiatrists\%2FDirectories\%2FLibrary-and-Archive\%2 Ftask-force-reports\%2Ftfr2003_PatientSafety.pdf\&usg=AOvVaw2i3 XdEFsJjakrX8cHXDwOU Accessed Jan 292019.

28. Ayani N, Sakuma M, Morimoto T, Kikuchi T, Watanabe K, Narumoto J, et al. The epidemiology of adverse drug events and medication errors among psychiatric inpatients in Japan: the JADE study. BMC Psychiatry. 2016 Aug 30;16:303.

29. Hanrahan NP, Kumar A, Aiken LH. Adverse events associated with organizational factors of general hospital inpatient psychiatric care environments. Psychiatr Serv. 2010;61:569-74.

30. LeGates TA, Kvarta M, Thompson SM. Sex differences in antidepressant efficacy. Neuropsychopharmacology. 2019;44:140-54

31. [What was noted by The Swedish Health and Social Care Inspectorate (IVO) 2017? The most important observations in IVO's supervision and authorizing during 2017.] In Swedish. 2018. https://www.ivo.se/globalassets/dokument/ publicerat/rapporter/rapporter-2018/vad-har-ivo-sett-2017.pdf accessed Jan 292019.

32. Danielsson M, Nilsen P, Rutberg H, Årestedt K. A national study of patient safety culture in hospitals in Sweden. J Patient Saf. 2019;15:328-33.

33. Bent-Ennakhil N, Cécile Périer M, Sobocki P, Gothefors D, Johansson G, Milea $\mathrm{D}$, et al. Incidence of cardiovascular diseases and type 2 diabetes mellitus in patients with psychiatric disorders. Nord J Psychiatry. 2018;72:455-61.

34. Bauer-Staeb C, Jörgensen L, Lewis G, Dalman C, Osborn DPJ, Hayes JF. Prevalence and risk factors for HIV, hepatitis $B$, and hepatitis $C$ in people with severe mental illness: a total population study of Sweden. Lancet Psychiatry. 2017:4:685-93.

35. Compton MT, Daumit GL, Druss BG. Cigarette smoking and overweight/ obesity among individuals with serious mental illnesses: a preventive perspective. Harv Rev Psychiatry. 2006;14:212-22.

\section{Publisher's Note}

Springer Nature remains neutral with regard to jurisdictional claims in published maps and institutional affiliations.
Ready to submit your research? Choose BMC and benefit from:

- fast, convenient online submission

- thorough peer review by experienced researchers in your field

- rapid publication on acceptance

- support for research data, including large and complex data types

- gold Open Access which fosters wider collaboration and increased citations

- maximum visibility for your research: over $100 \mathrm{M}$ website views per year

At BMC, research is always in progress.

Learn more biomedcentral.com/submissions 